
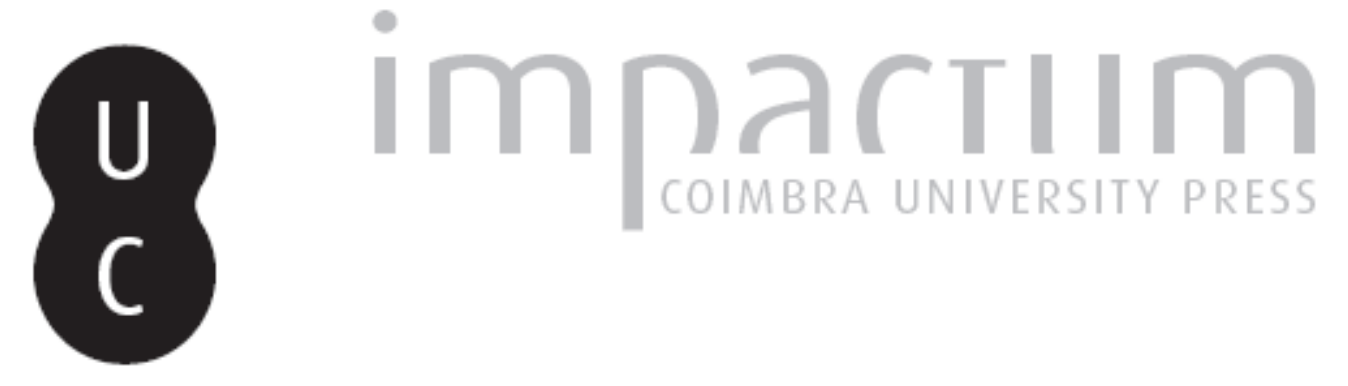

\title{
Gestão universitária: contradições entre privado e público
}

Autor(es): $\quad$ Sobrinho, José Dias

Publicado por: Fórum de Gestão do Ensino Superior nos Países e Regiões de Língua

URL

persistente:

URI:http://hdl.handle.net/10316.2/36218

DOI:

DOI:http://dx.doi.org/10.14195/2183-2722_1-1_3

Accessed : $\quad$ 26-Apr-2023 11:57:09

A navegação consulta e descarregamento dos títulos inseridos nas Bibliotecas Digitais UC Digitalis, UC Pombalina e UC Impactum, pressupõem a aceitação plena e sem reservas dos Termos e Condições de Uso destas Bibliotecas Digitais, disponíveis em https://digitalis.uc.pt/pt-pt/termos.

Conforme exposto nos referidos Termos e Condições de Uso, o descarregamento de títulos de acesso restrito requer uma licença válida de autorização devendo o utilizador aceder ao(s) documento(s) a partir de um endereço de IP da instituição detentora da supramencionada licença.

Ao utilizador é apenas permitido o descarregamento para uso pessoal, pelo que o emprego do(s) título(s) descarregado(s) para outro fim, designadamente comercial, carece de autorização do respetivo autor ou editor da obra.

Na medida em que todas as obras da UC Digitalis se encontram protegidas pelo Código do Direito de Autor e Direitos Conexos e demais legislação aplicável, toda a cópia, parcial ou total, deste documento, nos casos em que é legalmente admitida, deverá conter ou fazer-se acompanhar por este aviso.

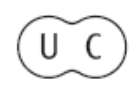




\section{REVISTA}
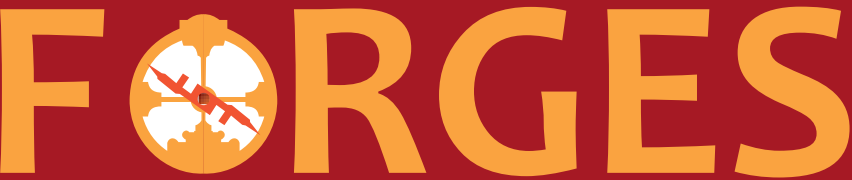

Fórum da Gestão do Ensino Superior nos Países e Regiões de Língua Portuguesa

Ensino Superior

Organizadores

Sônia Fonseca | Luísa Cerdeira |

Tomás Patrocínio
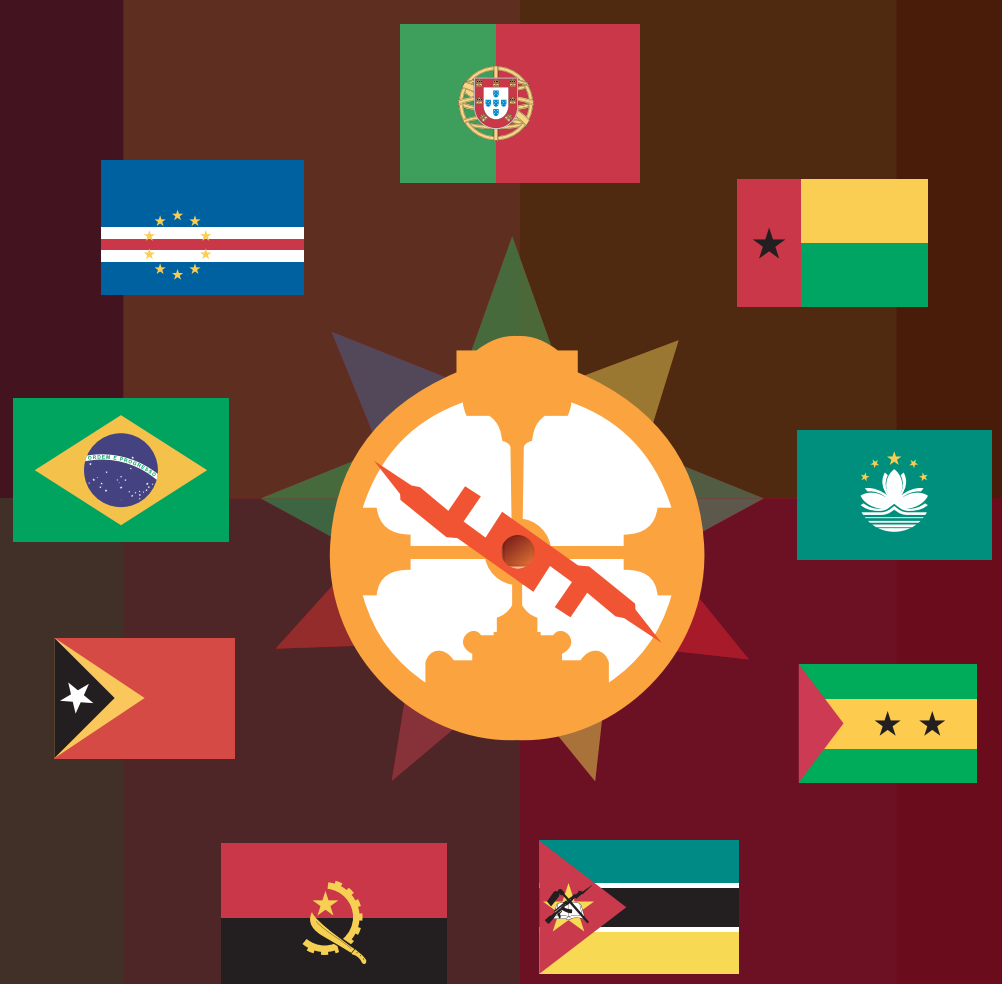


\title{
3
}

\section{Gestão Universitária: contradições en- tre privado e público}

\author{
José Dias Sobrinho'
}

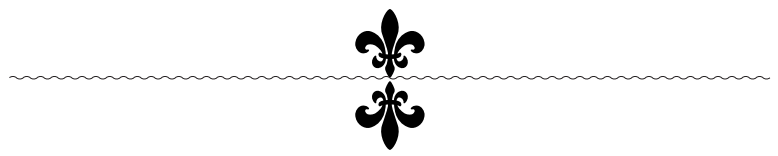

Nada se edifica sobre a pedra, tudo sobre a areia, mas nosso dever éedificar como se fora pedra a areia... (Borges, Evangelho Apócrifo, n 41)

Basti em hommes, non en pierres (François I, 1530, sobre a Escola dos Leitores Reais).

Resumo: Este artigo trata de contradições entre duas concepções de universidade prevalentes no Brasil desde a década de 1990. Uma, que corresponde ao modelo ainda hoje predominante nas universidades privadas e em certos aspectos de instituições públicas, será denominada universidade operacional (Chauí, 2001: 189). A outra concepção, que respeita os princípios da educação como bem público, foi explicitada neste artigo mediante a apresentação de uma experiência de gestão democrática realizada na Universidade Estadual de Campinas (Unicamp), com destaque ao processo de avaliação institucional levado a cabo entre 1990 e 1994.

Palavras chave: Universidade, gestão universitária, gestão empresarial, gestão democrática, avaliação institucional.

\section{Contexto neoliberal da universidade operacional}

Um novo modelo de civilização fundado sobre a economia global e informacional vem sendo imposto a todas as dimensões da

1 Professor titular do Programa de Pós-graduação em Educação da Universidade de Sorocaba. E.mail: jose.sobrinho@prof.uniso.br 
vida humana, notadamente desde as duas últimas décadas do século passado. Países, organizações, instituições, indivíduos, quase nada e quase ninguém estão imunes às determinações econômicas, ideológicas, políticas e culturais do neoliberalismo do atual momento do capitalismo. Esse novo senso comum geral destruiu boa parte das velhas estruturas civilizacionais, tanto em aspectos práticos da vida, como as transformações no mundo do trabalho, da produção e do consumo, quanto no campo da moral, dos costumes e dos sentidos da existência humana. Não apenas os meios se transformam. O mais fundamental é a transformação dos significados das finalidades (dos objetivos, das missões ou dos fins).

Uma das mais notáveis mudanças de finalidades vem ocorrendo na educação; de modo especial, na educação superior, pois aí se produzem conhecimentos e se formam indivíduos. O que há de especial nisso é que os conhecimentos são hoje importantes ativos econômicos e a formação se reduz a preparação de mão de obra. $\mathrm{O}$ novo modelo civilizacional imposto pelo neoliberalismo precisou reformar as antigas instituições e os velhos organismos, ou mesmo criar outros com novas características de atuação e finalidades. Essa nova conjuntura produziu importantes formas de desorganização nas relações entre estruturas tradicionais. Na lógica neoliberal, eficiência e produtividade necessitariam da diminuição do estado (e consequentemente, do governo central) e desregulação e flexibilização do mercado (ou das relações entre produção e consumo). $\mathrm{O}$ universo ideológico e prático do lucro e do individualismo possessivo ganhou forte protagonismo no mundo contemporâneo.

As mudanças que o neoliberalismo vem produzindo no campo educativo apresentam muitos matizes. Terminologia, conceitos, percepções e expectativas distintas dos diversos atores (professores, estudantes, pais, políticos, empresários, sindicatos e associações profissionais) constituem um campo complexo em que não há consensos absolutos. Mas, em que pesem as contradições, podem-se destacar sentidos dominantes e tendencialmente globais que apontam para importantes diferenças da educação neoliberal destas últimas três décadas e meia com relação às formas e crenças básicas do liberalismo.

De um modo ou de outro, todas as mudanças impostas pelo neoliberalismo estão produzindo fortes impactos na educação supe- 
rior. A abertura dos mercados e a liberalização do comércio fornecem as bases para a segurança jurídica e alimentam a ideologia da educação como produto comercializável, inclusive sem as barreiras das fronteiras físicas entre países e mercados. A redução do estado promovida pela economia de mercado e a presença das intervenções governamentais mais limitadas aos resultados e desempenhos favorece os processos de privatização e a crença da supremacia do privado sobre o público. A glorificação do mercado livre justifica as políticas e programas que diminuem a participação estatal em gastos dos serviços sociais e os entrega às iniciativas privadas, inclusive fazendo crer que estas são mais eficientes. A ideologia neoliberal trata de convencer que educação, saúde e outras áreas de interesse público, se privatizadas, são mais eficientemente resolvidas.

A economia de mercado não tem produzido os frutos prometidos, se pudéssemos considerá-la somente do ponto de vista exclusivamente econômico. Ao contrário, as crises de fundo econômico brotaram e ainda irrompem em vários países do mundo, inclusive nos centrais, acarretando graves problemas de ordem política e social e conflitos em todos os níveis. Dos pontos de vista social e econômico, em muitas partes do mundo, aumentaram as brechas entre ricos e pobres. Mas, diferentemente dos fracassos econômicos, a ideologia neoliberal viceja amplamente. Já há algumas gerações de jovens que cresceram imbuídos naturalmente das crenças e dos comportamentos que constituem o senso comum neoliberal e que passaram a ocupar postos de prestígio nos círculos da administração, da indústria e do comércio, da política e dos meios de comunicação, da educação formal e informal. Enfim, muitos dos jovens que nasceram e cresceram sob o domínio do modelo neoliberal se destacam em diversos setores econômicos e em distintas estruturas sociais.

Na universidade, o neoliberalismo engendrou um novo ethos, com transformações na gestão, nas práticas pedagógico-científicas, nas relações interpessoais, nos contratos de trabalho, nas relações com a sociedade e com as agências governamentais etc. Não se trata apenas de alterações relativas aos meios e práticas: fundamentalmente, são transformações que atingem frontalmente os objetivos, missões e finalidades da educação superior. De instituição de formação integral do ser humano, a universidade tende a ser instrumento do mercado. De instituição autônoma e livre para criar e criticar 
de acordo com os princípios públicos e os valores superiores da humanidade, desloca-se para a funcionalização dos interesses mercadológicos e individualistas que sustentam o capitalismo acadêmico.

O enfraquecimento das políticas públicas e as iniciativas de desregulação da educação superior têm presença dominante desde o início da década de mil novecentos e oitenta. Thatcher e Reagan são dois artífices fundamentais dessas mudanças que se impuseram como instrumentos poderosos do neoliberalismo. Gestão eficiente e gerencialismo passaram a ser expressões de alto conteúdo ideológico. Participação da comunidade, permitindo mais possibilidades de escolha por parte dos consumidores, introduziu um elemento de mercado ao substituir a ideia de política pública por iniciativas inspiradas na gestão empresarial. A lógica amplamente difundida é a seguinte: não importa quem provê, importante é que haja liberdade de escolha para o consumidor dos serviços educacionais. Para isso, quanto mais e diferenciados provedores, mais leques de opção haveria. Fato é que a adoção desse modelo introduziu altos níveis de competição nos sistemas educativos. Coerentemente, a competitividade é ideologizada como fator de eficiência, eficácia e produtividade.

A exigência de eficácia, num quadro de forte competitividade, requer gestão eficiente. E a ideologia trata de propagar que a gestão tal como praticada no setor privado é mais eficiente e, até mesmo, instrumento de equidade. O mercado funciona como um juiz neutro entre interesses contraditórios, dando ganho de causa à competência, à eficiência e à eficácia, supostamente mais apropriadas pelas instituições privadas. Essas mudanças produzem, de um lado, maior desresponsabilização do estado no tocante à oferta de oportunidades e diminuição dos investimentos no sistema educacional. Por outro lado, aumentam as responsabilidades das comunidades locais, dos gestores, professores e estudantes. Os estados estimulam a ampliação do provimento principalmente privado, concedendo maior liberdade de criação e gestão das instituições e cursos, mas controlando os resultados e desempenhos por meio de vários instrumentos de regulação, comparação e avaliação de larga escala, em nível nacional e internacional.

A ideologia, para tornar-se hegemônica, precisa ter o apoio de poderosos operadores. No caso do neoliberalismo, dos mais importantes são os organismos internacionais: Banco Mundial, Organização 
para a Cooperação e o Desenvolvimento Econômico, Organização Mundial do Comércio etc. Num conhecido documento de 1994, o Banco Mundial (adaptando para a educação superior recomendações mais gerais do Consenso de Washington), preconizava, entre outras coisas: redução do investimento público; incentivo à privatização para aumentar a equidade; defesa da comercialização da educação superior; supremacia de aspectos comerciais sobre os educacionais. Além disso, esse documento alinhava-se às propostas da OMC de considerar a educação como uma commodity à qual se aplicam as facilidades e leis do comércio internacional (Banco Mundial, 1994).

Ganha destaque a questão da gestão: há que ser eficiente, à maneira da gestão empresarial. Sem responsabilidades maiores com a sociedade, sem levar em conta a secular autonomia e as liberdades acadêmicas, sem outra missão além da satisfação do cliente e os ganhos de competitividade, pressupostos do lucro.

De acordo com Neave, as dificuldades econômicas do início da década de 1980 produziram respostas que passaram a ter dois componentes essenciais: o estado avaliador, que reformula as relações entre educação e governo, e um segundo que se refere às relações entre educação e sociedade. Diz Neave que esta segunda dimensão é uma "tentativa de impor uma forma determinada de ética competitiva, definida desde o exterior, como a força impulsora primordial do desenvolvimento institucional e, portanto, do sistema" educacional. (Neave, 1988: 7 -8, apud Whitty, Power, Halpin, 1999: 55). Ao estado avaliador não importam muito os processos, e sim os resultados, em conexão com os objetivos da economia.

No campo educacional, ocorre um deslocamento das finalidades sociais para as demandas do mercado, coerentemente com a passagem do estado de bem-estar social para o estado neoliberal. Esse deslocamento exige mudanças nas estruturas administrativas das instituições. O compromisso com o bem-estar dos indivíduos e com os valores democráticos da sociedade cede lugar para um tecnicismo supostamente neutro. Adquirem protagonismo os executivos e gestores. Estes devem ser capazes de levar as instituições a darem as respostas requeridas pelo mercado e de corresponder aos mecanismos de controle postos em ação pela administração central.

A racionalidade técnica substitui os valores da solidariedade e da cooperação pela competitividade e a valorização do indivíduo. 
Em vez do cidadão, o cliente. Não a formação, e sim a funcionalização econômica. No lugar dos valores sociais e do interesse público, assumem protagonismo o eficientismo e a relação custo-benefício, base do conceito de eficácia. Mesmo a colegialidade, quando ocorre, se assemelha mais a mecanismos impostos que propriamente colaborativos, não reconhecendo que a construção do sujeito e dos processos cognitivos são essencialmente sociais e públicos.

Se, no passado, a educação superior cumpria um papel importante na reprodução das relações de poder segundo os interesses das elites, no neoliberalismo ela se transforma em produtora de força de trabalho e assume prioritariamente a função de capacitação de mão de obra para o mercado. O mais importante a observar a esse respeito é que, segundo a lógica neoliberal, essa preparação para o trabalho, para a maioria dos futuros empregados, não deve ir além de um adestramento técnico que não ofereça ao aprendiz as condições para o exercício de críticas e de autoavaliação dos processos laborais a que está submetido.

A partir dos anos oitenta do século passado, universidade e as demais instituições de educação superior, especialmente as de caráter explicitamente lucrativo, passaram a adotar em suas organizações e administrações o modelo das empresas comerciais. Isso significa, segundo esclarece Marilena Chauí (2001: 56), que elas têm "o rendimento como fim, a burocracia como meio e as leis do mercado como condição". Vale a pena explorar um pouco mais os argumentos apresentados por essa autora.

Com base em livro de Michel Freitag (Le naufrage de l'Université, Paris, La Découverte, 1996), Chauí (2001: 187) desenvolve a distinção entre organização social e instituição social. A organização social definese pela prática da instrumentalidade: "está referida ao conjunto de meios (administrativos) particulares para a obtenção de um objetivo particular". Suas "estratégias são balizadas pelas ideias de eficácia e de sucesso no emprego de determinados meios para alcançar o objetivo particular que a define". Continua Chauí: "Por ser uma administração, é regida pelas ideias de gestão, planejamento, previsão, controle e êxito". Portanto, a organização é autorreferente, voltada para si mesma. Só lhe interessam a eficácia, o lucro, o sucesso em termos particulares, e não os objetivos sociais. Pertence à categoria da rivalidade, não do bem comum. É movida pela competitividade, 
não pela solidariedade. Distintamente, uma instituição social, diz ainda Chauí (2001: 187) inspirada no texto de Freitag, "tem a sociedade como seu princípio e sua referência normativa e valorativa".

Obviamente, como em outras épocas, as transformações que vêm ocorrendo na educação superior guardam forte relação com as mudanças da sociedade em geral. Neste último meio século de que estou falando, as mudanças da condição de instituição para a de organização estão intensamente vinculadas ao processo de acumulação capitalista. A passagem de uma condição à outra na educação superior brasileira recebe um primeiro forte impulso na reforma de 1968, sob determinação do governo militar. Chauí marca as três etapas dessa mudança: "Numa primeira etapa, tornou-se universidade funcional; na segunda, universidade de resultados; e na terceira, operacional" (2001: 189). Esses três momentos marcantes da história brasileira recente correspondem, respectivamente, ao dito "milagre econômico" dos anos 70, sob o regime ditatorial militar, à incipiente abertura política dos oitenta e ao neoliberalismo dos noventa.

A universidade funcional priorizava a formação rápida de mão de obra qualificada para atender às necessidades do projeto de desenvolvimento industrial então impulsionado pelos militares. A universidade de resultados foi pródiga na expansão privada, com o intuito de atender a demanda crescente da classe média, e impulsionou as parcerias com as empresas. A universidade operacional (denominação dada por Freitag) dos anos noventa se organiza e se guia pelo objetivo de eficácia, assegurada pela gestão e planejamento competentes. Diz Chauí (2001: 190): “Definida e estruturada por normas e padrões inteiramente alheios ao conhecimento e à formação intelectual, está pulverizada em microrganizações que ocupam seus docentes e curvam seus estudantes a exigências externas".

$\mathrm{Na}$ universidade operacional, processos de transmissão e adestramento prevalecem sobre a reflexão, a crítica, a autonomia de pensamento. Numa palavra, a ideia de capacitação profissional sobrepõe-se à finalidade essencial da educação, que é a formação integral do indivíduo, em todas as suas dimensões pessoais, sociais, intelectuais, morais, políticas e tudo o mais que constitui o ser humano. Isso não significa que restam abolidas as contradições. $\mathrm{Na}$ educação, como em qualquer âmbito social, debatem-se ideologias, valores e interesses de distintas naturezas e perspectivas que muitas 
vezes se opõem à visão de mundo do neoliberalismo hegemônico, isto é, da economia de mercado que caracteriza a atual etapa da acumulação capitalista.

$\mathrm{Na}$ universidade operacional têm centralidade as crenças e práticas eficientistas, produtivistas, objetivistas e tecnicistas. Uma gestão eficaz, essa é a crença propalada, produziria os resultados planejados. Eficácia, produtividade e rentabilidade formam um eixo conceitual de uma organização bem sucedida. No jargão corrente, essa aliança constitui a noção de excelência empresarial ou até mesmo institucional. $\mathrm{O}$ desempenho competente dos técnicos asseguraria o adequado funcionamento da organização e, consequentemente, o lucro do capital e a satisfação dos clientes. Concorrência e competitividade passaram a ser palavras chave, nos níveis individual, institucional, empresarial, nacional e internacional. Individualismo possessivo, darwinismo social, lucro, consumismo, competência, eficiência, produtividade e outras do mesmo campo semântico são expressões que constituem o universo ideológico do neoliberalismo e estruturam a modelação das consciências acorde com os desígnios do sistema dominante.

Em grossas pinceladas, esse é o cenário da universidade brasileira dos últimos cinco decênios. A seguir, será detalhada uma experiência de gestão que se deu entre 1990 e 1994, numa universidade pública. $\mathrm{O}$ autor destas linhas desempenhava-se no cargo de Pró-reitor de Pós-graduação da Universidade Estadual de Campinas (Unicamp), sendo Carlos Vogt o reitor. Essa informação é necessária, pois poderá justificar, ao menos parcialmente, o tom inevitavelmente pessoal e subjetivo do tratamento da matéria que será dada a seguir. Desde logo cabe admitir a grande dificuldade, até mesmo a impossibilidade, de evitar completamente as nuanças de subjetivismo num texto que tenta recuperar uma experiência protagonizada pelo próprio autor.

Intencionalmente, será dada ênfase àqueles aspectos da experiência a ser relatada que de alguma forma não compactuavam com a visão gerencialista e operacional que prevalecia, ao menos como tendência geral, no contexto universitário brasileiro da época (e que ainda hoje prevalece). Não cabe aqui fazer balanços de falhas e de sucessos. Importa, sim, apresentar brevemente os aspectos teóricos e práticos de uma experiência situada e datada, admitindo 
sem constrangimentos que projetos e programas nunca são perfeitos. Como é óbvio, frequentemente ocorrem muitas dissensões e distanciamentos entre intenções e realizações, especialmente em fenômenos sociais de alta complexidade, como os que constituem uma instituição educativa. Em que pesem todas as falhas e insuficiências, pôr em ação projetos que buscam a construção e a elevação da qualidade educativa, científica e social é em si mesmo um valor a ser reconhecido.

\section{1990-1994: Uma experiência de gestão democrática}

É nesse cenário anteriormente apresentado que desponta a Universidade Estadual de Campinas (Unicamp). Sua criação na segunda metade dos anos sessenta integrava-se aos anseios e projetos de desenvolvimento nacional. Surgia como universidade que deveria investir pesadamente na produção de pesquisa básica e no desenvolvimento da tecnologia, ser competente na capacitação de mão de obra para a indústria emergente e atenta às novas demandas da economia em processo de modernização. A universidade, entendida no projeto do governo militar daqueles anos como lugar da capacitação qualificada do "capital humano", era instada a cumprir uma função estreitamente vinculada á produção industrial e ao mercado de trabalho, estruturando programas e processos de pesquisa sistemática em áreas de alto interesse do ponto de vista do planejamento estratégico concebido e praticado pela aliança entre indústria e governo nacional. No projeto nacional dominado pela ideia megalomaníaca de fazer do Brasil uma grande potência mundial, tornaram-se fundamentais as instituições de pesquisa, a formação de pesquisadores e docentes para o ensino superior em expansão e a capacitação de quadros técnicos para a indústria. Desde seus primórdios, a Unicamp aderiu a esse modelo.

Evidentemente, a pesquisa, a formação de pesquisadores e de quadros de alta qualificação em vista das necessidades de desenvolvimento nacional são funções extremamente importantes das universidades. Entretanto, isso não deve sobrepor-se aos compromissos da formação integral dos indivíduos, do aprofundamento das condições de cidadania, do fortalecimento das estruturas e vivências de 
sociedades democráticas, da transcendência a valores universais da humanidade. No mínimo, que a universidade não perca seus valores essenciais como lugar de formação e emancipação humana e não se submeta passivamente aos desígnios do mercado que substitui valores por preços. Formação de cidadãos e emancipação humana não se contrapõem aos imperativos de qualificação profissional e desenvolvimento nacional fundamentado na expansão das bases do conhecimento. Ao contrário, são coessenciais.

A ênfase nos processos científico-tecnológicos tem sido a marca principal da Unicamp, desde seus primórdios. O aparato de pesquisa e de formação de pesquisadores se desenvolveu sistemática e continuamente, materializando-se na criação de laboratórios, cursos de pós-graduação em todas as áreas do conhecimento, relações com as empresas e o entorno social, crescente titulação pós-graduada de professores, cooperação com investigadores internacionais, grande número de estudantes em nível de mestrado e de doutorado (até mesmo superior ao número de alunos de graduação) etc..

No período aqui destacado (1990 - 1994), a gestão da Unicamp seguiu os lineamentos gerais do denominado Projeto Qualidade, cujos eixos principais serão apresentados nos próximos parágrafos. Antes, porém, cabe dizer que a qualidade aí referida se concebia como articulação das diversas dimensões que constituem o conjunto complexo das finalidades de uma instituição universitária. Em outras palavras, a qualidade que se tinha como referência consistia na superação de falsas dicotomias entre ensino, pesquisa, extensão, administração, universidade e sociedade, tendo como foco e finalidade a formação plena dos estudantes e sua inserção crítica e criativa na construção da sociedade. A qualidade não era, assim, uma simples questão de eficácia e de competência técnica; tinha uma dimensão muito forte de sentido humano e social.

1.Autonomia. A consolidação dos mecanismos democráticos e institucionais de uma universidade pública não poderia ocorrer sem uma autêntica autonomia. Mas só faz sentido a autonomia numa instituição efetivamente pública na medida em que ela assegura as condições básicas para a promoção da qualidade. Numa instituição realmente pública, a qualidade tem um sentido muito distinto do que lhe é comumente atribuído numa organização privada. Não se refere tão somente ao lucro, à eficácia e aos interesses particulares, mas 
à responsabilidade frente aos imperativos superiores da sociedade relativamente à produção de conhecimentos científica e socialmente relevantes e do cumprimento da finalidade essencial da formação integral. A relevância científica alia-se à pertinência social.

A Unicamp já gozava de autonomia no exercício de suas atividades acadêmicas de ensino, pesquisa e extensão, mas, somente após 1989 passou a ter os benefícios e a responsabilidade da gestão financeira autônoma. A autonomia financeira aprofundou o sentido de responsabilidade compartilhada. A gestão da instituição deixou de ser vista como sendo problema e responsabilidade somente dos que ocupam cargos administrativos. Esse misto de mais liberdade e mais responsabilidade produziu vários efeitos positivos para a consolidação da universidade, como ficará mais claro nos itens seguintes. Mas desde logo cabe ressaltar que a autonomia financeira, correlata do uso adequado, responsável e eficiente da dotação orçamentária, contribuiu fortemente para instaurar a experiência dos limites e possibilidades dos recursos e, sobretudo, a ideia de que uma universidade pública é uma construção permanente e dever de todos, guardados os respectivos lugares e papéis institucionais.

2.Todo o aparato estrutural físico e as práticas didático-científicas e administrativas da universidade requerem a segurança jurídica e normativa da institucionalidade, de acordo com procedimentos de participação democrática em todas as instâncias. Grande empenho foi dado à consolidação das Comissões e Congregações nos Institutos e Faculdades, em conexão com as instâncias da administração superior, tais como Pró-reitorias e respectivas Câmaras e o Conselho Universitário. O forte sentido de institucionalidade reforçou ainda mais o caráter público e democrático das atividades científicas, pedagógicas e administrativas. Creio ser absolutamente correto pensar que a ampla participação da comunidade universitária e de representantes da sociedade exerceu um importante papel relacionado com os compromissos da educação com os valores públicos. Em artigo publicado em 1994, relatei o seguinte:

Num curto período de pouco mais de vinte anos, a Unicamp construiu o seu campus, organizou e desenvolveu as suas áreas científicas e pedagógicas, formou um qualificado corpo de docentes e pesquisadores, estruturou suas carreiras, amadureceu suas formas e seus conteúdos 
institucionais, conquistou sua autonomia e estabeleceu as prioridades do seu crescimento qualitativo (Dias Sobrinho, 1994, p. 38)

3.Avaliação. A melhoria constante de todo o conjunto complexo e plural da universidade só é possível pela participação de todos na construção de uma cultura institucional. Para isso são fundamentais os processos de avaliação que se debrucem sobre a qualidade científica e técnica de suas atividades de formação e de produção de conhecimentos e também, inseparavelmente, sobre as respostas da universidade às mais agudas demandas da sociedade, aí compreendidos o desenvolvimento econômico e sociopolítico e a melhoria dos sistemas educativos e culturais.

Desde logo, cabe esclarecer que essa avaliação não segue a mesma lógica, procedimentos e propósitos das avaliações elaboradas e impulsionadas por organismos representativos da big science, cujos produtos mais evidentes são os rankings internacionais e as práticas administrativas e pedagógicas que se ajustam às determinações de agências governamentais com o único objetivo de assegurar bons desempenhos da instituição nas comparações e nos processos regulatórios nacionais e supranacionais.

A avaliação na Unicamp no período em consideração seguia dois eixos correlacionados. Um consistia no acompanhamento individualizado das atividades de docência, pesquisa, extensão e participação na administração. Esse acompanhamento era realizado por uma Comissão que contou com a participação de representantes de todas as Unidades (Institutos e Faculdades) e da Administração Central da universidade. Após as manifestações das Congregações de cada Unidade, a Comissão de Avaliação do Desenvolvimento Institucional (CADI) emitia pareceres circunstanciados sobre os relatórios trienais de cada docente, emitindo julgamentos sobre o trabalho executado, apresentando sugestões no sentido de contribuir para a solução de dificuldades e, sobretudo, incentivando a integração de suas práticas aos objetivos institucionais. Um dos mais evidentes efeitos desse acompanhamento individualizado foi um notável aumento na titulação pós-graduada dos professores, nos níveis de mestrado e doutorado. (Atualmente, quase 100\% dos 
professores possuem título de doutorado). Importante a ressaltar que todo o trabalho da CADI se deu segundo procedimentos democráticos de participação, discussão, respeito pessoal e institucional e de apoio aos esforços de aperfeiçoamento dos docentes. Cabe destacar duas iniciativas de apoio aos docentes. 1). Um apoio financeiro para desenvolvimento de projetos visando à melhoria do ensino e/ou da pesquisa (FAEP, ao qual mais tarde se acrescentou o E da extensão). 2). Um programa de aperfeiçoamento de práticas didático-pedagógicas de estudantes de doutorado, sob a orientação de professores com grande experiência e dedicação ao magistério.

Seguem as linhas gerais da principal modalidade avaliativa desenvolvida nesse período: a avaliação institucional. Sua importância se deve à sua bem sucedida efetivação no nível interno e ao impacto que produziu no desenvolvimento de sistemas nacionais de avaliação institucional no Brasil e até mesmo em países da América do Sul. Esse destaque é lembrado por Hélgio Trindade, que fora reitor da Universidade Federal do Rio Grande do Sul e Coordenador da Comissão de Avaliação da Associação Nacional de Dirigentes das Instituições Federais de Educação Superior. Diz ele (Trindade, 1994: 4), referindo-se aos anos noventa: "iniciaram-se projetos mais amplos de avaliação institucional onde se destaca o da Universidade Estadual de Campinas desde 1991, que teve seus resultados divulgados em livro". Refere-se ao livro: Avaliação Institucional da Unicamp: Processo, Discussão e Resultados (publicado pela Unicamp em 1994).

Para além de ações avaliativas pontuais, a Avaliação Institucional da Unicamp "buscou empreender uma visão unitária da instituição, de caráter global e abrangente, através da articulação das diversas estruturas e relações" (Dias Sobrinho, 1994: 39). Partindo do princípio de que a qualidade é uma construção coletiva e não se limita às partes e sim ao conjunto institucional, o processo avaliativo da Unicamp buscava ser um instrumento de integração, de formação e de realização de melhorias em diversos âmbitos: científicos, pedagógicos, administrativos, institucionais, sociais etc.. Propunha-se ser um instrumento integrado à construção desse capital de valores comuns ou disputados que constitui a cultura universitária. Em dois sentidos ela se faz institucional: sendo um processo amplo e abrangente das diferentes dimensões institucionais 
e implicando a participação dos corpos docente, discente e administrativo, principalmente dos respectivos quadros de representação. $\mathrm{O}$ processo se realizou nas distintas instâncias, com variáveis graus de adesão e acertos, "numa dinâmica de diagnose, estudos, reflexões, discussões, elaboração coletiva de análises, julgamentos de valores e sistematização, indo dos departamentos às congregações e destas aos órgãos centrais" (Dias Sobrinho, 1994: 40).

Essa dimensão social do processo tem grande valor formativo. Produz e organiza conhecimentos sobre a instituição, potencializa as oportunidades de relacionamentos interpessoais e de trabalho, evidencia as contradições e as formas de construir entendimentos, questiona os valores da cultura institucional, produz críticas e propõe soluções... Os processos avaliativos exercidos democrática e participativamente carregam um sentido pedagógico muitas vezes mais importantes que os dados quantitativos obtidos via procedimentos meramente analíticos e objetivos. Essa questão é bem trabalhada por Aballéa. Para ele, as abordagens quantitativas

são parciais e não necessariamente as mais ricas de significação, sobretudo se não são prolongadas por uma reflexão sobre os dados que elas permitem produzir e que transforma precisamente uma soma de dados fatuais ou cifras em uma produção de informações úteis para a ação, portanto se elas não são prolongadas por uma reflexão por natureza qualitativa (Aballéa, 1989: 6).

A avaliação qualitativa é importante porque intervém na realidade ao longo do processo. Entretanto, não se considere uma oposição simples entre quantitativo e qualitativo. Essas duas dimensões são coessenciais; isto é, não há uma sem a outra, ambas se constituem reciprocamente.

A participação da comunidade em todos os momentos do processo é fundamental para que a avaliação seja um amplo trabalho de interrogação, análise e adesão aos principais objetivos institucionais. A adesão da comunidade requer garantias de credibilidade técnica, operacional e político-filosófica da avaliação a ser realizada. Maior e mais intensa será a adesão e se traduzirá em participação efetiva quanto mais o projeto se mostrar construtivo, e não punitivo e con- 
trolador. As discussões gerais, não sem contradições, devem chegar a alguns pontos centrais de entendimento comum. A delimitação do objeto é um deles. A Unicamp definiu que o mais importante a interrogar e avaliar, em seu interior, eram os processos científicos e pedagógicos integrados no ensino, na pesquisa e na extensão. Em resumo, priorizou a questão da produção e socialização do conhecimento (meio) e da formação (fim).

Buscando sempre construir uma visão de integralidade, a avaliação centrou-se nas Unidades de Ensino, Pesquisa e Extensão (Faculdades, Institutos, Centros e Núcleos) e em suas relações no conjunto das respectivas grandes Áreas: Tecnológicas, Saúde, Humanas, Ciências Exatas. A ênfase se deu nas relações internas de cada grande Área e de cada uma dessas com as demais, tentando uma compreensão na medida do possível integrada da totalidade institucional. Além disso, uma outra prioridade consistiu nas relações da Unicamp com a sociedade, de modo especial com o setor produtivo, com as Agências de Fomento à pesquisa, com os sistemas educacionais e culturais de diversos níveis, com o atendimento médico-hospitalar etc..

O processo de avaliação que estamos apresentando teve três etapas distintas: autoavaliação, avaliação externa e reavaliação. No plano interno, foram consolidados dados que serviram de foco para as reflexões coletivas que lhes atribuíram julgamentos de valor. Um roteiro geral flexível procurou assegurar uma desejável homogeneidade, permitindo, porém, a adoção de escolhas e complementações que melhor atendessem as especificidades de cada setor. De um modo geral, foram propostas explicitações, análises e reflexões sobre as principais marcas de cada Unidade, Núcleos e Centros, sobre os corpos docente, discente e administrativo, cursos, produção científica, infraestrutura, relações interpessoais, compromissos sociais, participação nas estruturas políticas da instituição, relacionamento com o sistema educacional etc.. Mais de 8.000 páginas, no total, consolidaram essas informações, análises e reflexões.

A avaliação externa contou com a participação de especialistas da comunidade científica e representantes de alguns setores da sociedade, indicados pelas respectivas associações e agências públicas. Cinco comissões externas, uma para cada grande área do conhecimento e outra para as atividades interdisciplinares, 
reuniram-se na Unicamp durante os meses de novembro e parte de dezembro de 1992 e discutiram o material de autoavaliação, visitaram instalações (principalmente laboratórios e bibliotecas), entrevistaram livremente professores, estudantes, servidores técnicos, empregadores e elaboraram pareceres circunstanciados sobre cada uma das áreas avaliadas.

No terceiro momento - reavaliação -, novo trabalho analítico, crítico e valorativo foi efetuado pelos membros da comunidade interna. Nessa etapa, se colocaram em questão a organização e o desenvolvimento do processo e, sobretudo, as convergências e divergências entre as avaliações interna e externa. Os gestores de cada Unidade se reuniram em comissões e elaboraram as sínteses relativas a cada área. Mais ainda: formularam propostas para ações futuras de melhoramento.

O conjunto do material produzido contendo os dados e as principais reflexões sobre o processo está sintetizado no livro: Avaliação Institucional da Unicamp: Processo, Discussão e Resultados. A publicação cumpriu um dever que é inerente a uma instituição pública. A avaliação da Unicamp, nesse período aqui tratado, teve muitas limitações e falhas. Mas teve grandes méritos, não somente para a própria instituição mas também para o sistema universitário brasileiro e até mesmo serviu de inspiração e base para processos avaliativos de alguns países latino-americanos. No Brasil, o PAIUB e, posteriormente, o SINAES, em sua concepção original, se beneficiam da experiência e das bases conceituais e procedimentais da avaliação da Unicamp. Apesar de reconhecer as imperfeições e insucessos em vários aspectos, reafirmo meu julgamento explicitado no livro mencionado:

"São de valores inestimáveis a busca de elaboração de um modelo, as tentativas através de esforços socializados de superação das dificuldades e divergências, a reflexão coletiva sobre a matéria comum que constitui a realidade universitária, a ruptura das resistências e bloqueios à implementação de ações avaliativas, seu caráter exemplar e seus efeitos recorrentes, os intercâmbios e o diálogo interuniversitário, a abertura ao social" (Dias Sobrinho, 1994: 99). 


\section{Conclusão}

Procurei mostrar neste breve artigo contradições entre duas concepções de universidade presentes desde a década de 1990 no Brasil, focalizando de modo especial seus respectivos modelos de gestão. Uma concepção, ainda hoje predominante nas universidades privadas e em certos âmbitos de instituições públicas, foi aqui tratada como constituindo a universidade operacional, conforme designação de Michel Freitag e retrabalhado por Marilena Chauí. A outra concepção, que respeita os princípios da educação como bem público, foi discutida neste artigo por meio da apresentação de uma experiência de gestão democrática realizada na Unicamp, com destaque ao processo de avaliação institucional levado a cabo entre 1990 e 1994.

Na primeira parte, enfatizei que nas últimas décadas o universo ideológico e prático do lucro e do individualismo possessivo adquiriu forte protagonismo. Argumentei que a redução do estado e a presença das intervenções governamentais mais limitadas aos resultados e desempenhos, por imposição da economia global de mercado, favorece enfaticamente os processos de privatização e sua sustentação ideológica que faz crer na prevalência do privado sobre o público. Esse contexto tem forte impacto sobre as finalidades da educação superior e produz mudanças importantes na gestão do sistema e das instituições. As palavras de ordem são eficácia, eficiência, competitividade, produtividade, rentabilidade, excelência e outras desse campo. E isso seria mais confiavelmente alcançável mediante uma gestão praticada à maneira da gestão empresarial, sem outra preocupação que o lucro do capitalista e a satisfação do cliente.

Marilena Chauí, inspirada em Michel Freitag, apresentou três das principais marcas da universidade brasileira a partir de 1970, sob as denominações seguintes: universidade instrumental, universidade de resultados e universidade operacional. Destaquei um pouco mais esta última, que se inicia na década de 1990, por coincidir seu início com a experiência de gestão que procurei mostrar a título de contraponto. A universidade operacional é aqui apresentada como o grande exemplo do modelo neoliberal de gestão, prevalente nas instituições privadas e, em alguns aspectos, também nas públicas.

Na segunda parte, apresentei uma experiência de gestão que 
acredito cumprir melhor os valores de uma gestão democrática inerentes a uma instituição pública. Trata-se de um conjunto de ações articuladas que visava incrementar a qualidade acadêmica, científica e administrativa nas diferentes instâncias da Unicamp. Um dos projetos centrais desse conjunto foi a avaliação institucional interna e externa realizada, com ampla participação da comunidade, entre 1990 e 1994. Esse foi o primeiro processo de avaliação institucional que se completou numa universidade brasileira. Foi exemplar, apresentou falhas e limitações, mas também produziu muitos efeitos positivos na Unicamp e serviu de inspiração a outros programas de avaliação que vieram a ser promovidos por muitas instituições e mesmo pelo sistema nacional (por exemplo, PAIUB e SINAES).

Importante observar que não há um modelo único de universidade. Tampouco há total homogeneidade em uma instituição, qualquer que seja ela. As contradições são inerentes aos fenômenos sociais, sempre insertos em interesses, valores e distintas orientações políticas. Também não há instituições prontas e acabadas. Elas se transformam nos incessantes movimentos de seus processos de construção. Esses processos não se realizam em nenhum vácuo, nem se fazem independentes dos seus tempos e lugares. Mas as boas experiências, ainda que devam ser atualizadas, criticadas e aperfeiçoadas, não devem ser esquecidas. 


\section{Referências}

ABALLÉA, F. (1989). L'Evaluation qualitative: approche méthodologique. In: Recherche sociale. Révue de la FORS, nํ111, Paris.

BANCO MUNDIAL. (1994). Higher education: The lessons of experience, Washington.

CHAUI, M. (2001). Escritos sobre a Universidade. São Paulo: Editora UNESP.

DIAS SOBRINHO, J. (1994). A Avaliação Institucional na Universidade Estadual de Campinas. Considerações Teóricas e Processo. Educación y Sociedad, v. 5, nº 1 y 2. Caracas: UNESCO/CRESALC, pp. 31 - 49.

DIAS SOBRINHO, J. (ed.). (1994b). Avaliação Institucional da Unicamp: Processo, Discussão e Resultados, Dias Sobrinho (org.). Campinas: Unicamp, 403 p.

FREITAG, M. (1996). Le naufrage de l'Université, Paris: La Découverte.

NEAVE, G. (1988): On the cultivation of quality, efficiency and enterprise: an overview of recent trends in higher education in Western Europe, 19681988, European Journal of Education, 23 (1/2).

TRINDADE, H. (1994). Apresentação. Educación y Sociedad, v. 5, no 1 y 2, Caracas: UNESCO/CRESALC, pp. 3-6.

WHITTY, G., POWER, S., HALPIN, D., (1999). La escuela, el estado y el Mercado, Madrid: Ediciones Morata. 